\title{
The Effect of Transfer Factor as Immunoprotective in Mice Challenged with Mycobacterium tuberculosis
}

\author{
Jamal Bayed S. ${ }^{1, *}$, Ahmed K. Bolad ${ }^{2}$ \\ ${ }^{1}$ Department of Medical Microbiology, Faculty of Medicine and health Sciences, University of Kassala, Kassala, Sudan \\ ${ }^{2}$ Al- Neelain University, Faculty of Medicine, Khartoum, Sudan \\ *Corresponding author: abumusab2008@gmail.com
}

\begin{abstract}
Background: Transfer Factor (TF) is an immune modulator which stimulates the cellular arm of the immune system (killer lymphocytes), activates immune cytokine synthesis and regulates immune function [1]. TF is very effective in those diseases in which CMI plays a relevant role in protection and control of the disease, such as intracellular bacterial diseases (tuberculosis) [2]. TF are low molecular weight products from immune cells that are able to transmit the ability to express delayed-type hypersensitivity (DTH) and cell mediated immunity (CMI) from sensitized donors to non immune recipients [3]. Objectives: The aim of this experimental study is to determine the protective efficacy of transfer factor (TF) as immunotprotective for mice. Materials and methods: A total number of 82 mice were examined for their immunopotency and protective efficacy of Transfer factor (TF) against challenge dose of $M$. tuberculosis $\left(10^{7} \mathrm{CFU}\right)$. A number of 20 mice were immunized with the attenuated strain of $M$. bovis, Bacillus Calmette-Guérin (BCG). After 21 days of BCG spleens of 10 tuberculous mice were removed aseptically for the preparation of TF. To evaluate the effect of TF 3 groups of inbred BALB/c male mice were injected with TF and challenged with virulent $M$. tuberculosis, All mice with TF were tested for tuberculin skin test (TST) so as to determine susceptibility and resistance against tuberculosis, susceptible groups of mice were challenged with virulent $M$. tuberculosis.Followed by study of humoral response by immunization of a group of mice with immune sera and challenged with M. tuberculosis H37Rv strain. Followed by an experiment of group A and B for the susceptibility and resistance of the strains of mice. Results: After three weeks of observations the mice of experiment were tested for tuberculin skin test and the results were positive. Effectiveness determination of TF as protective efficacy was $(83.3 \%)$. Humoral immunity response against $M$. tuberculosis showed negative reaction hence mortality rate was $100 \%$, group B mice were resistant for BCG (Swiss white strain). Conclusions: The results indicated that administration of murine transfer factor (mTF) extracted and prepared from spleen of animal model (mice) as immunoprotective for challenged mice of $M$. tuberculosis (H37Rv) showed a better results enhanced immune response in respect to delayed type hypersensitivity, survival rate and mortality rate suggesting that efficacy of mTF as immunotherapy for tuberculosis.
\end{abstract}

Keywords: Transfer Factor (TF), BCG, Mice and M. tuberculosis

Cite This Article: Jamal Bayed S., and Ahmed K. Bolad, "The Effect of Transfer Factor as Immunoprotective in Mice Challenged with Mycobacterium tuberculosis." American Journal of Microbiological Research, vol. 6, no. 1 (2018): 9-13. doi: 10.12691/ajmr-6-1-2.

\section{Introduction}

Transfer Factor (TF) is an immune modulator. The main function of these peptides in the body is to provide immune protection against microbes (bacteria, viruses, fungi, and protozoa), cancerous cells and other antigens capable of disturbing vital processes in the body. It stimulates the cellular arm of the immune system (killer lymphocytes), activates immune cytokine synthesis and regulates immune function [2]. TF have been demonstrated to be very effective in those diseases in which CMI plays a relevant role in protection and control of the disease, such as intracellular bacterial diseases (tuberculosis, leprosy) and parasite infections (leishmaniasis, toxoplasmosis) [2]. TF or leucocyte dialysates are low molecular weight dialysable products from immune cells that are able to transmit the ability to express delayed-type hypersensitivity (DTH) and cell mediated immunity (CMI) from sensitized donors to nonimmune recipients [3]. In 1955, Lawrence discovered that a dialyzed of viable leukocytes obtained from a healthy donor presenting a positive percutaneous tuberculin test was able to transfer to a healthy receptor the ability to respond to this pathogen. Lawrence named these molecules as Transfer Factor. TF is composed of peptide obtained from lymphocytes ranging from 3500-6000 kDa. $\mathrm{T}$ lymphocytes have the ability to express delayed-type hypersensitivity and cell mediated immunity from sensitized donors to non immune recipients. TF plays a vital role in controlling immune over reactions and mistargeted responses in the development of autoimmune reactions. $\mathrm{TF}$ improves cellular immunity in patients with immune deficits due to their responses are mediated by antigen- 
specific, inducer, and suppressor/regulatory activities contained in this fraction. Tuberculosis (TB) is primarily a chronic lung infection that is one of the most potent and wide-spread human infections today, and a major cause of death from bacterial pathogens [4]. It affects more young adults and therefore has a high impact on the socioeconomic status of people [5]. Although TB is a serious global health problem, several medical advances have been made in the past years to facilitate prevention and control of TB. In general, TB mortality started to decrease in most industrialized countries during the $20^{\text {th }}$ century, probably due to a better socioeconomic status including improved nutrition and living conditions [6] TB re-emerged during the 1990s both in developing and several industrialized countries partly due to the HIV/AIDS pandemic and also because of an increased emergence of drug resistant $M$. tuberculosis strains [7].

Transfer factor (TF) is shown to be capable of transferring antigen-specific cell-mediated immunity (CMI) to T lymphocytes and therefore TF can successfully be used as treatment for $M$. tuberculosis. and specially for MDR-TB and supplementary for conventional chemotherapy. The BCG based vaccine can provide stimulation of both innate and acquired immunity [8]. The incidence of TB is high inspite of primary vaccination in neonatal period.

\section{Materials and Methods}

A total number of 82 mice were examined for their immunopotency and protective efficacy of Transfer factor (TF) against challenge dose of M. tuberculosis ( $\left.10^{7} \mathrm{CFU}\right)$. A number of 20 mice were immunize with the attenuated strain of M. bovis, Bacillus Calmette-Guérin (BCG). After 21 days of BCG spleens of 10 tuberculous mice were removed aseptically for the preparation of TF. Three groups of mice were used $n=12$ for each group (36mice), the groups were $T_{1}, T_{2}$ and $T_{3}$ The mice of group $T_{1}$ and $T_{2}$ were given transfer factor (TF) and the mice of group $\mathrm{T}_{1}$ and $\mathrm{T}_{3}$ were challenged with $M$. tuberculosis.

Another group of mice $n=6$ for the study of humoral response by immunization of mice with immune serum and challenged with $M$. tuberculosis Following by two groups of mice $n=10$ for each group $A$ and $B$ for the susceptibility and resistance of the strains of mice by immunization of mice with BCG for 21 days and testing by tuberculin skin test (TST). The efficacy was based on a survival rate of challenged mice, mortality rate and susceptibility and resistance of the strains of mice by immunization of mice with BCG.

\subsection{Mycobacterium tuberculosis STRAIN}

Virulent M. tuberculosis H37Rv strain (American Type Culture collection) and. M. bovis BCG (Bacille Calmette Guerin) Collection strain 1011 were obtained from Kassala TB center (Kassala University) and Kassala Ministry of health.

\subsection{Animals}

Inbred BALB/c (8-12 weeks old) mice were obtained from Veterinary Research Laboratories in Khartoum,
Swiss mice (males 20-25grams) were obtained from Professor Hamid Suliman (U. of Khartoum.) All the mice were maintained in standard cages under sterile conditions and were fed commercial mice chow and water. All animals were housed and maintained in accordance with protocols approved by the Institutional Animal Care.

\subsection{Preparation of Murine Transfer Factors (mTF)}

A number of 20 mice were immunize with the attenuated strain of $M$. bovis, Bacillus Calmette-Guérin (BCG) by intrapritoneal (i.p) route with $0.5 \mathrm{ml}$ of a 10 fold dilution of BCG. After 21 days success of immunization was confirmed by tuberculin skin test. After 21 days of BCG spleens of 10 tuberculous mice were removed aseptically, chopped and grunt with clean sterile glass beads or sand and cell extract of immunized animals were distributed in $10 \mathrm{ml}$ normal saline or phosphate buffer saline (PBS) were used. The cell suspension was centrifuged to remove cellular debris at $1500 \mathrm{rpm}$ for 15 minutes and the upper layer were collected in sterile test tubes. RPMI 1640 media were added to the layer mixed well and then centrifuge at 2000 rpm for 2 hours till the separation of the component and appearance of middle layer. This middle layer which was $\mathrm{T}$ lmphocytes was collected with Pasteur pipette in test tubes and kept in deep freezer $\left(-70^{\circ} \mathrm{C}\right)$ and removed next day or till used. The test tube was thawed by keeping in room temperature before returning to the deep freezer $\left(-70^{\circ} \mathrm{C}\right)$. The process of freezing and thawing was repeated 18 times. The suspension was then centrifuged at $40000 \mathrm{rpm}$ for 30 minutes. The upper layer which was the transfer factor (TF) was then separated.

\subsection{Tuberculin Skin Test Procedure}

Intradermal injection of mice with $0.2 \mathrm{ml}$ of purified protein derivative (PPD) and then induration and swelling were observed in the skin of tested mice after 24-72 hours.

All the three groups were challenged with $(0.5 \mathrm{ml})$ virulent $M$. tuberculosis $\mathrm{H} 37 \mathrm{Rv}$ strain (American Type Culture Collection, ATCC 35718) M. tuberculosis. 107 (CFU).

\subsection{Challenge Dose}

Preparation of different concentration of M. tuberculosis by McFarland 0.5 and colony forming unit (CFU) of $10^{2}$, $10^{3}, 10^{4}$, up to $10^{9}$.

McFarland standards were made by mixing specified amounts of Barium chloride and Sulfuric acid together. Mixing the two compounds forms a Barium Sulfate precipitate, which causes turbidity in the solution. A 0.5 McFarland standard is prepared by mixing $0.05 \mathrm{ml}$ of $1.175 \%$ barium chloride dihydrate $\left(\mathrm{BaCl}_{2} \cdot 2 \mathrm{H}_{2} \mathrm{O}\right)$, with $9.95 \mathrm{ml}$ of $1 \%$ sulfuric acid $\left(\mathrm{H}_{2} \mathrm{SO}_{4}\right)$. The standard was compared visually to a suspension of bacteria in sterile saline or nutrient broth. If the bacterial suspension was too turbid, it was then diluted with more saline. If the suspension was not turbid enough, more bacteria was added. 


\subsection{Preparation of Inoculum for $\mathbf{L D}_{50}$ Determination of $M$. tuberculosis}

On the day of inoculation the optical density (O.D.540nm) of bacterial suspension of M. tuberculosis was adjusted to 1.35 and $1 \mathrm{ml}$ of suspension then serial dilutions $\left(10^{0}, 10^{1}, 10^{2}, 10^{3}, 10^{4}\right.$, up to $\left.10^{9}\right)$ were prepared in saline, for each dilution 6 mice of each group were inoculated with $0.5 \mathrm{ml}$ intrapritoneally. Inoculation of $0.5 \mathrm{ml}$ of different concentrations $10^{2}, 10^{3}, 10^{4}$, up to $10^{9}$ of $M$. tuberculosis. McFarland 0.5 intrapritoneally in a group of 10 mice for each concentration to determine the $\mathrm{LD}_{50}$. The concentration of the suspensions which kills $50 \%$ of the mice is the $\mathrm{LD}_{50}$.

The control group received normal saline $0.5 \mathrm{ml}$ intrpritoneally. Observations of the two groups were done for one week after the inoculation of different concentrations of $M$. tuberculosis and the normal saline were recorded. Lethal dose $\left(\mathrm{LD}_{50}\right)$ concentration which kills $50 \%$ of the mice was recorded.

Another group of mice $n=6$ for the study of humoral response by immunization of mice with immune serum and challenged with $M$. tuberculosis Following by two groups of mice $\mathrm{n}=10$ for each group $\mathrm{A}$ and $\mathrm{B}$ for the susceptibility and resistance of the strains of mice by immunization of mice with BCG for 21 days and testing by tuberculin skin test (TST). The efficacy was based on a survival rate of challenged mice, mortality rate and susceptibility and resistance of the strains of mice by immunization of mice with BCG for 21 days.

\section{Results}

\subsection{Results of Tuberculin Skin Test in BCG Immunized Mice}

A total number of 10 inbred $\mathrm{BALB} / \mathrm{c}$ mice were tuberculin skin test (TST) positive after immunization with BCG while 10 out bred Swiss white mice were negative for TST.

Table 1. The results of tuberculin skin test reaction (TST)

\begin{tabular}{|c|c|c|}
\hline Type of mouse strain & No. of mice/group & TST reaction \\
\hline BALB/c inbred susceptible mice & 10 & Positive \\
\hline Swiss out bred resistant mice & 10 & Negative \\
\hline
\end{tabular}

Immunization of mice with BCG for 21 days and testing by tuberculin skin test (TST).

\subsection{Results of $\mathrm{LD}_{50}$ Concentration}

Table 2 shows the groups of mice inoculated with different concentrations of $M$. tuberculosis. $\left(10^{2}, 10^{3}, 10^{4}\right.$, up to $10^{9}$ ) and the normal saline(control group) for one week showed that the group of colony forming unit (CFU) $\left(10^{0}\right)$ exhibited no death of mice. Mice given $\left(10^{1}\right)$ and $\left(10^{2}\right)$ were exhibited 2 deaths out of $10(2 / 10)$ i.e. mortality ratio $20 \%$ The groups of $\left(10^{3}\right)$ and $\left(10^{4}\right)$ showed 3 deaths out $10(3 / 10)$ i.e. mortality ratio $30 \%$. In the groups given $\left(10^{5}\right)$ and $\left(10^{6}\right) 4$ deaths out $10(4 / 10)$ mice showed mortality ratio $40 \%$, In the groups given $\mathrm{CFU}\left(10^{7}\right)$ of mice showed 5 deaths out of $10(5 / 10)$ with mortality ratio $50 \%$. This showed that the lethal dose $\left(\mathrm{LD}_{50}\right)$ which killed $50 \%$ of the total number of the mice.

Table 2. Shows the results of $\mathrm{LD}_{50}$ determination

\begin{tabular}{|c|c|c|c|}
\hline $\begin{array}{c}\text { No. of BALB/c } \\
\text { mice /group }\end{array}$ & $\begin{array}{c}\text { Bacterial } \\
\text { inoculums (CFU) }\end{array}$ & $\begin{array}{c}\text { No. of dead } \\
\text { mice }\end{array}$ & Mortality ratio \\
\hline 10 & $10^{0}$ & 0 & $0 \%$ \\
\hline 10 & $10^{1}$ & 2 & $20 \%$ \\
\hline 10 & $10^{2}$ & 2 & $20 \%$ \\
\hline 10 & $10^{3}$ & 3 & $30 \%$ \\
\hline 10 & $10^{4}$ & 3 & $30 \%$ \\
\hline 10 & $10^{5}$ & 4 & $40 \%$ \\
\hline 10 & $10^{6}$ & 4 & $40 \%$ \\
\hline 10 & $10^{7}$ & 5 & $50 \%$ \\
\hline 10 & $10^{8}$ & 6 & $60 \%$ \\
\hline 10 & $10^{9}$ & 7 & $70 \%$ \\
\hline
\end{tabular}

$\mathrm{LD}_{50}\left(\mathrm{CFU}\left(10^{7}\right)\right)$ is the $\mathrm{LD}_{50}$ at which $50 \%$ of the mice were killed.

\subsection{Results of the Response of Murine Transfer Factor (mT.F) in Protection against Challenge}

The results of the groups of mice which were injected with mTF were exhibited in Table 3. The control group $\left(\mathrm{T}_{3}\right)$ which were not immunized with mTF exhibited $100 \%$ mortality after 24 hours of virulent HRv37 with M.tuberculosis. The second group $\left(\mathrm{T}_{2}\right)$ which received mTF but not challenged with $M$. tuberculosis survived $100 \%$. The third group $\left(\mathrm{T}_{1}\right)$ which received $\mathrm{mTF}$ and challenged with $M$. tuberculosis 10 out of $12(10 / 12)$ mice survived after 3 weeks of observation and (2/12) were died and hence protection of T.F immunopotency was $83.3 \%$.

Table 3. The results of effectiveness determination of murine Transfer Factor in mice challenged with M. tuberculosis

\begin{tabular}{|c|c|c|c|c|c|c|}
\hline $\begin{array}{l}\text { Group of } \\
\text { mice }\end{array}$ & $\begin{array}{l}\text { Number of BALB/c } \\
\text { mice/group }\end{array}$ & $\begin{array}{c}\text { Dose of } \\
\text { T.F./mouse }\end{array}$ & $\begin{array}{l}\text { Challenge dose of } \\
\text { M.tb. }\end{array}$ & $\begin{array}{l}\text { No.of dead } \\
\text { mice }\end{array}$ & $\begin{array}{l}\text { Mortality } \\
\text { rate } \%\end{array}$ & $\begin{array}{l}\text { Protective } \\
\text { efficacy } \%\end{array}$ \\
\hline $\mathbf{T}_{1}$ & 12 & $0.5 \mathrm{ml}$ & $0.5 \mathrm{ml}$ & 2 & $\begin{array}{l}(2 / 12) \\
16.7 \%\end{array}$ & (10/12) $83.3 \%$ \\
\hline $\mathbf{T}_{2}$ & 12 & $0.5 \mathrm{ml}$ & _ & 0 & $0 \%$ & $100 \%$ \\
\hline $\mathbf{T}_{3}$ (control) & 12 & - & $0.5 \mathrm{ml}$ & 12 & $\begin{array}{c}(12 / 12) \\
100 \%\end{array}$ & $0 \%$ \\
\hline
\end{tabular}




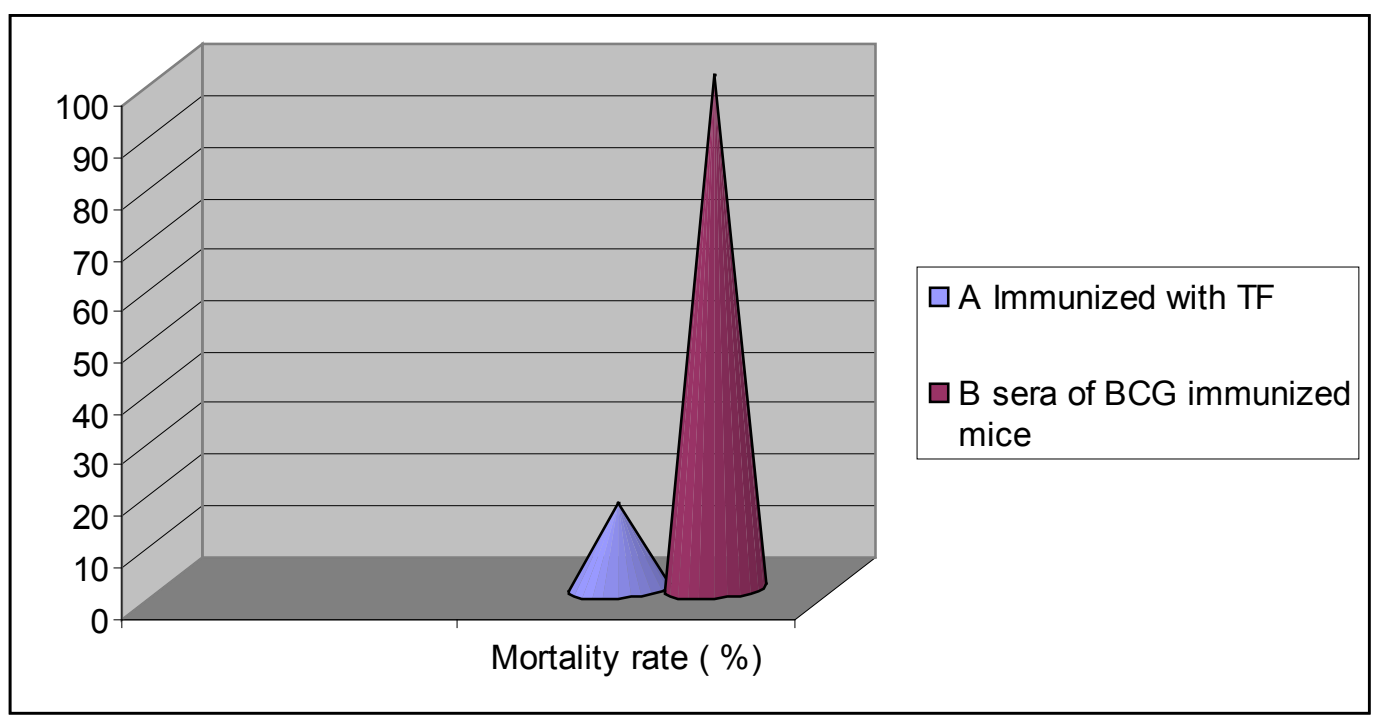

Figure 1. Shows Humoral response of mice against Mycobacterium tuberculosis compared with transfer factor (TF) mortality rate

\subsection{The results of Humoral Response of Mice against Mycobacterium tuberculosis}

The result was death of the mice within 24 hours, and mortality rate of humoral response of mice against Mycobacterium tuberculosis was $100 \%$ compared with $16.7 \%$ mortality rate of transfer factor (TF). (Figure 1)

\section{Discussion}

Since the discovery of Transfer Factor (TF) by Sherwood Lawrence in1955, more than 60 years ago Transfer Factor has been found to be very effective in those diseases in which CMI plays a relevant role in protection and control of the disease, such as viral infections (herpes simplex, varicella zoster), intracellular bacterial diseases (tuberculosis, leprosy) and parasitic infections (leishmaniasis, toxoplasmosis) and some types of cancer. Transfer Factor (TF) are protein that transfer the ability to express cell mediated immunity from immune donors to non-immune recipients. $\mathrm{TF}$ treatment were found to selectively affects cytokine production in response to antigenic stimulation [9]. In this study transfer factor obtained from the spleen of mice which were immunized by BCG intrapritoneally (I.P.) for twenty one days. The peak of immune protection in this animal model reached in day 21. This agree with a study done by Fabre [10] in Mexico, used Transfer Factor as immunotherapy and supplement of chemotherapy in experimental pulmonary tuberculosis [10]. The current study found that the effect of administration of murine transfer factor (TF) on survival of challenged mice was majority $(83.3 \%)$ comparing with maximum (100\%) mortality of the control group, and this result obtained is in accordance with a study done in Mexico 2004 by Fabre (Transfer factors as immunotherapy and supplement of chemotherapy in experimental pulmonary tuberculosis)where they found that the BALB/c mice which were infected via the trachea with Mycobacterium tuberculosis $\mathrm{H} 37 \mathrm{Rv}$ and treated with mTF showed a significant $95 \%$ survival when compared with the control group, which exhibited $100 \%$ mortality.
Mexican team of investigators have shown that treatment of mice infected with M. tuberculosis with a murine tuberculosis-specific TF restored expression of the Th1 cytokine pattern and resulted in inhibition of bacterial proliferation, significant increase of DTH, and animal survival [10]. The efficiency of TF was highly depended on the dose and, to its source (murine, human or bovine),colostrums is rich in transfer factor.4lifeTransfer Factor, American company is famous and well known in the production of TF.

Susceptible mice, which are often able to contain bacterial growth in the liver and spleen, are unable to restrict growth in the lung. While granulomas in resistant mice are well organized, consisting of aggregated lymphocytes and macrophages, lesions in susceptible mice are often poorly organized, necrotic and contain few lymphocytes. This implies that susceptible strains have a defect in recruiting or retaining lymphocytes in the lung. The production of cytokines crucial for the control of tuberculosis, such as IFNg, is usually diminished in susceptible mice, resulting in a general delay in the effect or phase of the adaptive immune response. In many cases, susceptible mice are deficient in maintaining a single dose [11].

\section{Conclusion}

The results indicated that administration of murine transfer factor (mTF) extracted and prepared from spleen of animal model (mice) as immunotherapy for challenged mice of M. tuberculosis (H37Rv) showed a better results enhanced immune response in respect to delayed type hypersensitivity, survival rate was (83.3\%) and mortality rate $(16.7 \%)$, comparing with the results of Humoral response of mice against Mycobacterium tuberculosis which was death of the mice within 24 hours, and hence mortality rate of humoral response of mice against Mycobacterium tuberculosis was $100 \%$.therefore response of mice against Mycobacterium tuberculosis was by cellular immunity (CMI) and not by humoral response (antibodies). Inbred strains of mice exhibit varied patterns of susceptibility following infection with virulent 
$M$ tuberculosis. Susceptible mice have progressive fulminate disease resulting in their premature death; in contrast, resistant mice are able to control bacterial replication, limit lung injury and survive longer.

\section{References}

[1] Lawrence HS (June 1965). "Transfer factor and autoimmune disease". Ann. N. Y. Acad. Sci. 124 (1): 56-60.

[2] Estrada Parra S, Chavez Sanchez R, Ondarza Aguilera R, Correa MB, Serrano MA, Monges NA, Calva PC (1995). Immunotherapy with transfer factor of recurrent herpes simplex type1. Arch Med Res. 26: S87-S92.

[3] Kirkpatrick, C. H. (2000). "Transfer factors: Identification of conserved sequences in transfer factor molecules". Molecular medicine (Cambridge, Mass.) 6 (4): 332-341.

[4] Lawn, S.D. and A.I. Zumla (2011)., Tuberculosis. Lancet 378 (9785): p. 57-72.

[5] Zakham F, Lahlou O, Akrim M, Bouklata N, Jaouhari S, Sadki K, (2012). Comparison of a DNA Based PCR Approach with
Conventional Methods for the Detection of Mycobacterium tuberculosis in Morocco. Mediterr. J. Hematol. Infect. Dis.4: 1-6. 24: 213-217.

[6] Lienhardt, C., (2012). Global tuberculosis control: lessons learnt and future prospects.Nature reviews. Microbiology, 10(6): $\mathrm{p}$. 407-16.

[7] Dheda, K., Kunst H, Gibson (2010). The immunology of tuberculosis: from bench to bedside.Respirology,. 15(3): p. 433-50

[8] Schreiber F, Huo Z, Giemza R, Woodrow M, Fenner N, Stephens $Z$, (2010). An investigation of clinical and immunological events following repeated aerodigestive tract challenge infections with live Mycobacterium bovis Bacille Calmette Guerin. Vaccine.; 28(33): 5427-31.

[9] Alvarez-Thull L, Kirkpatrick C H. (1996). Profiles of cytokine production in recipients of transfer factors. (Biotherapy $9(1-3)$ $55-9$.

[10] Fabre R A, Perez T M, Aguilar, L D, Rangel M J, Estrada-Garcia I, Hernandez-Pando R, and Estrada Parra S (2004). Transfer factors as immunotherapy and supplement of chemotherapy in experimental pulmonary tuberculosis Clin Exp Immunol 136(2): 215-223.

[11] Flynn JL, Goldstein MM, Triebold KJ, Sypek J, Wolf S, Bloom BR. (1995). IL-12 increases resistance of BALB/c mice to Mycobacterium tuberculosis infection. J Immunol; 155. 